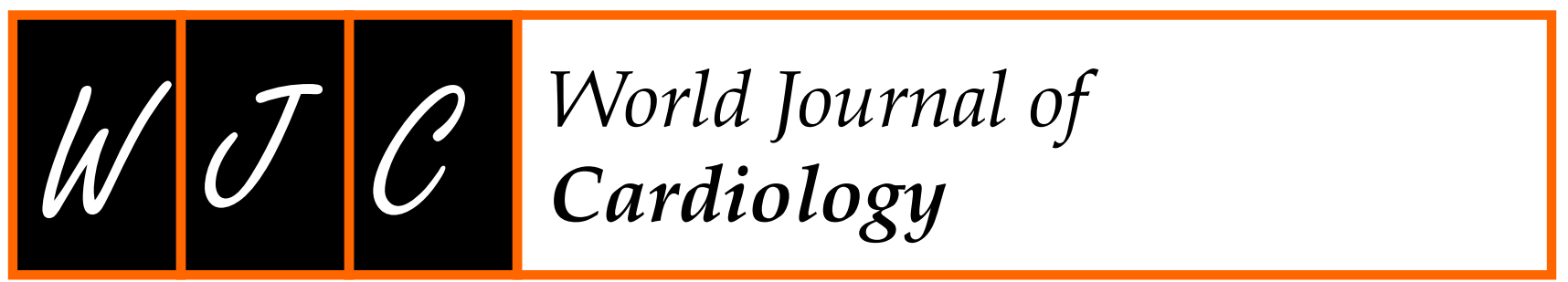

\title{
Prevalence and clinical characteristics associated with left atrial thrombus detection: Apixaban
}

\author{
Hoyle L Whiteside, Arun Nagabandi, Kristen Brown, Deepak N Ayyala, Gyanendra K Sharma
}

\author{
ORCID number: Hoyle L Whiteside \\ (0000-0002-7181-2482); Arun \\ Nagabandi \\ (https://orcid.org/0000-0002-1668-697 \\ 0); Kristen Brown \\ (https://orcid.org/0000-0002-5589-717 \\ 2); Deepak N Ayyala \\ (https://orcid.org/0000-0002-7251-580 \\ X); Gyanendra K Sharma \\ (https://orcid.org/0000-0001-9027-444 \\ $0)$.
}

Author contributions: Whiteside HL wrote the manuscript; Whiteside HL, Nagabandi A and Sharma GK reviewed and revised the final version of the manuscript; Whiteside HL, Nagabandi A and Sharma GK designed the study; Whiteside HL, Nagabandi A and Brown K coordinated and provided the data collection; Ayyala DN provided statistical consultation and analysis.

\section{Institutional review board} statement: The Institutional Review Board of Augusta University reviewed and approved this study on February 8, 2017.

Informed consent statement: This study was a retrospective analysis utilizing data readily available within the electronic medical record system. The study received a waiver of the consent process upon review by the Institutional Review Board and the dataset was stored electronically on an institutional research drive.

Conflict-of-interest statement: The authors report no financial relationships or conflicts of interest regarding the content.

Open-Access: This article is an
Hoyle L Whiteside, Kristen Brown, Division of Internal Medicine, Medical College of Georgia at Augusta University, Augusta, GA 30912, United States

Arun Nagabandi, Gyanendra K Sharma, Division of Cardiology, Medical College of Georgia at Augusta University, Augusta, GA 30912, United States

Deepak N Ayyala, Division of Biostatistics and Data Science, Department of Population Health Sciences, Medical College of Georgia at Augusta University, Augusta, GA 30912, United States

Corresponding author: Hoyle L Whiteside, MD, Doctor, Division of Internal Medicine, Medical College of Georgia at Augusta University, $112015^{\text {th }}$ St., Augusta, GA30909, United States.hwhiteside@augusta.edu

Telephone: +1-706-7212423

Fax: $+1-706-7211059$

\section{Abstract}

\section{BACKGROUND}

The prevalence of left atrial appendage (LAA) thrombus detection by transesophageal echocardiogram (TEE) in patients with non-valvular atrial fibrillation (AF) anticoagulated with apixaban is not well defined and identification of additional risk factors may help guide the selection process for pre-procedural TEE. The purpose of our study was to retrospectively analyze the prevalence of LAA thrombus detection by TEE in patients continuously anticoagulated with apixaban for $\geq 4 \mathrm{wk}$ and evaluate for any cardiac risk factors or echocardiographic characteristics which may serve as predictors of thrombus formation.

\section{AIM}

To retrospectively analyze the prevalence of LAA thrombus detection by TEE in patients continuously anticoagulated with apixaban.

\section{METHODS}

Clinical and echocardiographic data for 820 consecutive patients with AF undergoing TEE at Augusta University Medical Center over a four-year period were retrospectively analyzed. All patients (apixaban: 226) with non-valvular AF and documented compliance with apixaban for $\geq 4 \mathrm{wk}$ prior to index TEE were included.

\section{RESULTS}

Following $\geq 4$ wk of continuous anticoagulation with apixaban, the prevalence of 
open-access article which was selected by an in-house editor and fully peer-reviewed by external reviewers. It is distributed in accordance with the Creative Commons Attribution Non Commercial (CC BY-NC 4.0) license, which permits others to distribute, remix, adapt, build upon this work non-commercially, and license their derivative works on different terms, provided the original work is properly cited and the use is non-commercial. See: http:/ / creativecommons.org/licen ses/by-nc/4.0/

\section{Manuscript source: Unsolicited} manuscript

Received: October 24, 2018 Peer-review started: October 24, 2018

First decision: December 10, 2018

Revised: December 18, 2018

Accepted: January 8, 2019

Article in press: January 9, 2019

Published online: February 26, 2019
LAA thrombus and LAA thrombus/dense spontaneous echocardiographic contrast was $3.1 \%$ and $6.6 \%$, respectively. Persistent AF, left ventricular ejection fraction $<30 \%$, severe LA dilation, and reduced LAA velocity were associated with thrombus formation. Following multivariate logistic regression, persistent AF (OR: 7.427; 95\%CI: 1.02 to 53.92; $P=0.0474$ ), and reduced LAA velocity (OR: 1.086; $95 \% \mathrm{CI}$ : 1.010 to $1.187 ; P=0.0489$ ) were identified as independent predictors of LAA thrombus. No Thrombi were detected in patients with a $\mathrm{CHA}_{2} \mathrm{DS}_{2}-\mathrm{VASc}$ score $\leq 1$.

\section{CONCLUSION}

Among patients with non-valvular $\mathrm{AF}$ and $\geq 4$ wk of anticoagulation with apixaban, the prevalence of LAA thrombus detected by TEE was $3.1 \%$. This suggests that continuous therapy with apixaban does not completely eliminate the risk of LAA thrombus and that TEE prior to cardioversion or catheter ablation may be of benefit in patients with multiple risk factors.

Key words: Atrial fibrillation; Anticoagulation; Left atrial appendage thrombus; Transesophageal echocardiography

CThe Author(s) 2019. Published by Baishideng Publishing Group Inc. All rights reserved.

Core tip: The prevalence of left atrial appendage (LAA) thrombus detection by transesophageal echocardiogram (TEE) in patients with non-valvular atrial fibrillation (AF) anticoagulated with apixaban is not well defined and identification of additional risk factors may help guide the selection process for pre-procedural TEE. At our institution, the prevalence of thrombus detection in patients compliant with apixaban was $3.1 \%$. Persistent AF, left ventricular ejection fraction $<30 \%$, severe LA dilation, and reduced LAA velocity were associated with thrombus formation. Following multivariate logistic regression, persistent AF and reduced LAA velocity were identified as independent predictors of thrombus detection.

Citation: Whiteside HL, Nagabandi A, Brown K, Ayyala DN, Sharma GK. Prevalence and clinical characteristics associated with left atrial thrombus detection: Apixaban. World $J$ Cardiol 2019; 11(2): 84-93

URL: https://www.wjgnet.com/1949-8462/full/v11/i2/84.htm DOI: https://dx.doi.org/10.4330/wjc.v11.i2.84

\section{INTRODUCTION}

Atrial fibrillation (AF) is the most common sustained cardiac arrhythmia and is associated with increased risk of systemic thromboembolism due to the development of left atrial (LA) and LA appendage (LAA) thrombi ${ }^{[1,2]}$. Among patients with nonvalvular $\mathrm{AF}, 90 \%$ of atrial thrombi are seen within the $\mathrm{LAA}^{[3]}$. Transesophageal echocardiography (TEE) is the most sensitive and specific imaging modality for the detection LA thrombi and is routinely utilized in patients undergoing elective cardioversion or catheter ablation to reduce the risk of thromboembolic events ${ }^{[1,2,4-7]}$. Risk factors such as structural heart disease, left atrial size, reduced left ventricular ejection fraction (LVEF), persistent $\mathrm{AF}$, an $\mathrm{CHA}_{2} \mathrm{DS}_{2}-\mathrm{VASc}$ score have been reported as independent predictors of LAA thrombus detection by TEE ${ }^{[8-13]}$.

Several randomized trials have demonstrated the efficacy of non-vitamin $\mathrm{K}$ dependent oral anticoagulants (NOACs) to reduce rates of stroke and systemic thromboembolism compared to warfarin, however, their impact on the detection of LA thrombi by TEE is less well established ${ }^{[14,15]}$. In patients receiving $\geq 3 \mathrm{wk}$ of continuous anticoagulation with warfarin, the prevalence of LA thrombus detection is reported to be between $1.55 \%$ and $7.7 \%^{[8,12,13,16-20]}$. Recent data has helped to elucidate the prevalence of LA thrombi in patients anticoagulated with NOACs, particularly in patients prescribed dabigatran or rivaroxaban prior to catheter ablation ${ }^{[18-20]}$. With regards to apixaban, data remains limited ${ }^{[18-22]}$. With at least one study reporting a decline in utilization of TEE prior to catheter ablation and prescription rates for NOACs increasing on a yearly basis, further analysis of patients prescribed apixaban could have clinically meaningful implications ${ }^{[22,23]}$. Identification of additional risk 
factors which may predict LAA thrombus detection in patients prescribed apixaban is of particular interest as it could help identify a population which would be at increased risk of adverse outcomes should intervention be performed without TEE.

\section{MATERIALS AND METHODS}

\section{Study population}

Following institutional review board approval, we retrospectively identified 820 consecutive patients with a diagnosis of AF undergoing TEE at Augusta University Medical Center between January 1, 2014 and September 30, 2017 (Figure 1). We excluded 146 patients who were not on any anticoagulation, 183 patients anticoagulated with other NOACs (Rivaroxaban: 122, Dabigatran: 60, Edoxaban: 1), 221 patients anticoagulated with Warfarin, and 15 patients who were determined to be incorrectly coded as AF and in whom TEE was performed for an alternative indication. Two hundred fifty-five patients were anticoagulated with apixaban. Within this cohort, 13 patients were excluded due to documented non-compliance with continuous oral anticoagulation in the $4 \mathrm{wk}$ preceding index TEE, 8 for LAA ligation, 2 for valvular AF, and 6 patients with incomplete echocardiographic data. The final study population included 226 patients anticoagulated with apixaban.

\section{Data extraction and baseline assessment}

A detailed chart review was conducted in accordance with the study protocol targeting cardiac risk factors, anticoagulant therapy, and echocardiographic data. A $\mathrm{CHA}_{2} \mathrm{DS}_{2}-\mathrm{VASc}$ score was calculated for each patient in accordance with Lip et al ${ }^{[24]}$ AF lasting $\leq 7 \mathrm{~d}$ or $>7 \mathrm{~d}$ was defined as paroxysmal and persistent, respectively ${ }^{[1,2]}$. All physician notes in the four weeks preceding TEE were reviewed. Any patient with documented medication noncompliance was excluded from the study.

\section{Cardiac imaging}

TEE Imaging was performed using Phillips EPIQ 7 ultrasound machine and Phillips IE33 ultrasound transducer (Andover, Massachusetts). Standard TEE images were acquired including focused imaging of the LA and LAA. Technique routinely used at our institution involves acquisition of at least two orthogonal views of the LAA. All TEEs were reviewed by at least one of two echocardiographers with strong agreement between observers (Cohen's kappa: 0.89). A thrombus was reported if a wellcircumscribed, echo-reflective mass distinct from the LA endocardium or pectinate muscles was present in the appendage or body of the $\mathrm{LA}^{[4]}$. Spontaneous echo contrast (SEC) was classified as dense, clearing, or absent correlating with 3-4+, 1-2+, or 0 as graded by Fatkin et al ${ }^{[25]}$ SEC was classified as dense if a dense swirling pattern was observed in the LAA and was detectable throughout the cardiac cycle (with variable intensity). SEC was classified as clearing if minimal echodensity was observed in the LAA and was detectable transiently during the cardiac cycle. LAA velocities were determined based on peak velocities averaged over a minimum of two full cardiac cycles in the view which was most parallel to the LAA ostium. LA size was assessed semi-quantitatively and documented as normal, mildly, moderately, or severely dilated.

\section{Follow up}

For any patient with LA or LAA thrombi identified on TEE, data was collected for 180 $\mathrm{d}$ following index study. If a subsequent TEE was performed between 30 and $180 \mathrm{~d}$ following diagnosis of LA or LAA thrombi, then follow up data was collected including changes in oral anticoagulation, antiplatelet therapy, and resolution of thrombus.

\section{Statistical analysis}

All statistical computations and hypothesis tests were performed using R 3.4.3 (https://www.r-project.org/). To compare demographics and echocardiographic variables between groups, Fisher's exact test was used for categorical variables and Welch's $t$-test was used for the continuous variables. All hypothesis tests were performed at $5 \%$ significance level. Univariate logistic regression model was used to associate the odds of occurrence of an event (LAA thrombus formation, dense SEC) to demographic and echocardiographic factors. For scenarios where the odds of the event are zero, pseudo-data points were added to obtain valid estimates and test statistics. Significance of the factors was determined using a two-sided $z$-test. For each univariate model, a two-sided $95 \%$ confidence interval (CI) is reported. Using the variables deemed as significant, a multivariate logistic regression was fit to study independence of the variables. 


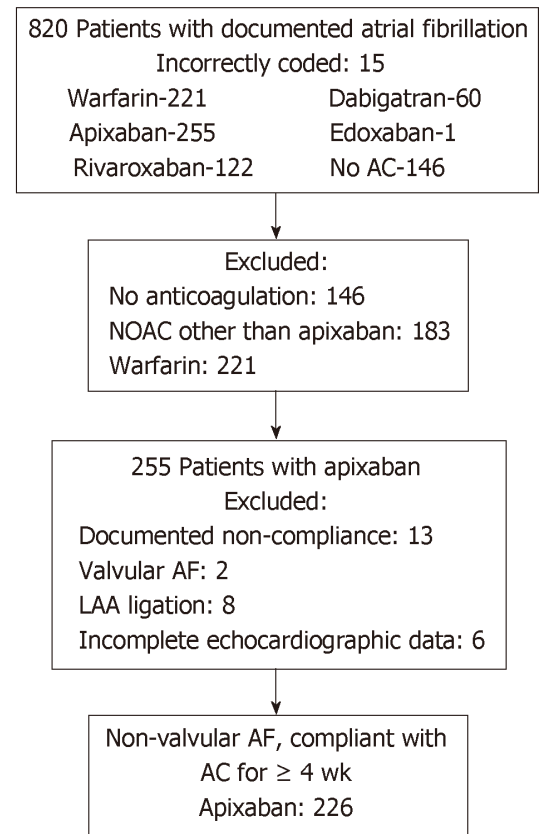

Figure 1 Study population. AC: Anticoagulation; AF: Atrial fibrillation; LAA: Left atrial appendage; NOAC: Nonvitamin $\mathrm{K}$ oral anticoagulant.

\section{RESULTS}

\section{Population demographics and echocardiographic characteristics}

Patient demographics, cardiac risk factors and echocardiographic characteristics for patients with and without thrombus detection are reported in Table 1. The presence of end-stage renal disease, persistent AF, reduced LAA velocities, severe LA dilation, and dense SEC were more common in patients found to have LAA thrombus. Overall, the study population was at meaningful risk of thromboembolic events as $181(80.1 \%)$ patients had $\mathrm{CHA}_{2} \mathrm{DS}_{2}-\mathrm{VASc}$ score $\geq 2$.

\section{Prevalence of LAA thrombus and SEC}

In patients compliant with apixaban, the prevalence of LAA thrombus and LAA thrombus/Dense SEC was $3.1 \%$ and $6.6 \%$, respectively. Full data for the study population based on prevalence of thrombus is provided in Table 1. A similar table, based on the prevalence of thrombus/dense SEC, is available in the online materials (Supplementary Table 1). Among patients with LVEF $<30 \%$ and $\geq 50 \%$, thrombus was detected in $9.1 \%$ and $2.0 \%(P=0.074)$, respectively. The prevalence of LAA thrombus based on $\mathrm{CHA}_{2} \mathrm{DS}_{2}-\mathrm{VASc}$ score is summarized in Supplementary Table 2. Notably, no thrombi were identified in the $45(19.9 \%)$ patients with a $\mathrm{CHA}_{2} \mathrm{DS}_{2}-\mathrm{VASc}$ score $\leq 1$.

\section{Univariate and multivariate predictors of LAA thrombus}

In patients anticoagulated with apixaban, persistent $\mathrm{AF}, \mathrm{LVEF}<30 \%$, severe LA dilation, and reduced LAA velocity were identified as univariate predictors of LAA thrombus detection (Table 2). On multivariate logistic regression, persistent AF (OR: 7.427; $95 \% \mathrm{CI}$ : 1.02 to $53.92 ; P=0.0474)$, and reduced LAA velocity (OR: 1.086 ; $95 \% \mathrm{CI}$ : 1.010 to $1.187 ; P=0.0489$ ) remained independent predictors of LAA thrombus detection. On further analysis, the OR for each 10\% decrease in LVEF was 1.517 (95\% CI: 0.971 to $2.369 ; P=0.067$ ). For the combined endpoint of LAA thrombus detection/dense SEC, reduced LAA velocity (OR: 1.131; 95\% CI: 1.031 to $1.235 ; \mathrm{p}=$ $0.0061)$, was a significant independent predictor on multivariate logistic regression with persistent AF (OR: 4.665; 95\%CI: 0.81 to $27.0 ; P=0.0856)$ and severe LA dilation (OR: 5.915 ; 95\% CI: 0.74 to $46.98 ; P=0.0927$ ) approaching significance (Supplementary Table 3).

\section{Subsequent cardiac imaging and thrombus resolution}

Six patients had a subsequent TEE performed 30-180 d following the diagnosis of LAA thrombus and documented compliance with continuous anticoagulation. Anticoagulation and echocardiographic data, as well as, $\mathrm{CHA}_{2} \mathrm{DS}_{2}-\mathrm{VASc}$ score for each patient is provided in Table 3 . These patients were anticoagulated for a mean of 
Table 1 Cardiac risk factors and echocardiographic characteristics by presence of thrombus

\begin{tabular}{|c|c|c|c|c|}
\hline & Study population ( $n=226$ ) & Apixaban-thrombus ( $n=7)$ & Apixaban - no thrombus ( $n=219)$ & $P$-value \\
\hline Age & $65.8 \pm 11.9$ & $68.1 \pm 8.0$ & $65.7 \pm 11.9$ & 0.458 \\
\hline \multicolumn{5}{|l|}{ Race } \\
\hline White & $190(84.1)$ & $4(57.1)$ & $186(84.9)$ & 0.0825 \\
\hline Black & $34(15.0)$ & $3(42.9)$ & $31(14.2)$ & 0.0712 \\
\hline Hispanic & $0(0)$ & $0(0)$ & $0(0)$ & - \\
\hline Asian & $2(0.9)$ & $0(0)$ & $2(0.9)$ & 1 \\
\hline Most recent $\mathrm{Cr}$ & $1.01 \pm 0.33$ & $1.18 \pm 0.82$ & $1.01 \pm 0.32$ & 0.662 \\
\hline ESRD & $6(2.7)$ & $2(28.5)$ & $4(1.8)$ & 0.012 \\
\hline Clopidogrel & $7(3.1)$ & $0(0)$ & $7(3.2)$ & 1 \\
\hline Aspirin & $83(36.7)$ & $2(28.5)$ & $81(37.0)$ & 1 \\
\hline $\mathrm{CHA}_{2} \mathrm{DS}_{2}$-VASc & $2.83 \pm 1.62$ & $3.43 \pm 1.40$ & $2.81 \pm 1.62$ & 0.354 \\
\hline $\mathrm{CHF}$ & $88(34.5)$ & $3(42.9)$ & $75(34.2)$ & 0.695 \\
\hline Hypertension & $184(81.4)$ & $7(100)$ & $177(80.8)$ & 0.353 \\
\hline Age $>75$ & $50(22.1)$ & $1(14.3)$ & $49(22.4)$ & 1 \\
\hline Diabetes & $50(22.1)$ & $2(28.5)$ & $48(21.9)$ & 0.652 \\
\hline Stroke & $11(4.9)$ & $0(0)$ & $11(5.0)$ & 1 \\
\hline Vascular disease & $26(11.5)$ & $1(14.3)$ & $25(11.4)$ & 0.580 \\
\hline Age $>65$ & $145(64.2)$ & $6(85.7)$ & $139(63.5)$ & 0.426 \\
\hline Female & $87(38.5)$ & $2(28.5)$ & $85(38.8)$ & 0.710 \\
\hline Persistent AF & $59(26.1)$ & $5(71.4)$ & $54(24.7)$ & 0.014 \\
\hline \multicolumn{5}{|l|}{ Echocardiographic data } \\
\hline LVEF & $47.8 \pm 14.3$ & $38.6 \pm 19.3$ & $48.1 \pm 14.1$ & 0.241 \\
\hline LVEF $<30$ & $33(14.6)$ & $3(42.9)$ & $30(13.7)$ & 0.066 \\
\hline LVEF 30-49 & $44(19.5)$ & $1(14.3)$ & $43(19.6)$ & 1 \\
\hline $\mathrm{LVEF} \geq 50$ & $149(65.9)$ & $3(42.9)$ & $146(66.7)$ & 0.233 \\
\hline LAA velocity & $48.4 \pm 18.1$ & $27.8 \pm 10.5$ & $49.0 \pm 18.0$ & 0.001 \\
\hline LAA velocity $<40 \mathrm{~cm} / \mathrm{s}$ & $71(31.4)$ & $6(85.7)$ & $65(29.7)$ & 0.004 \\
\hline \multicolumn{5}{|l|}{ SEC classification } \\
\hline None & $206(91.2)$ & $1(14.3)$ & 205 (93.6) & $<0.001$ \\
\hline Clearing & $7(3.1)$ & $1(14.3)$ & $6(2.7)$ & 0.200 \\
\hline Dense & $13(5.8)$ & $5(71.4)$ & $8(3.7)$ & $<0.001$ \\
\hline \multicolumn{5}{|l|}{ LA dilation } \\
\hline Moderate & $66(29.2)$ & $1(14.3)$ & $65(29.7)$ & 0.677 \\
\hline Severe & $59(26.1)$ & $6(85.7)$ & $53(24.2)$ & 0.001 \\
\hline \multicolumn{5}{|l|}{ Mitral Regurgitation } \\
\hline Moderate & $53(23.5)$ & $1(14.3)$ & $52(23.7)$ & 1 \\
\hline Severe & $5(2.2)$ & $1(14.3)$ & $4(1.8)$ & 0.147 \\
\hline
\end{tabular}

${ }^{1} P$-values denote differences between cohorts with and without thrombus. AF: Atrial fibrillation; CHF: Congestive heart failure; Cr: Creatinine; ESRD: Endstage renal disease; LA: Left atria; LAA: Left atrial appendage; LVEF: Left ventricular ejection fraction; SEC: Spontaneous echo contrast.

$94.0 \mathrm{~d}$ and thrombus resolution occurred in $83.3 \%$

\section{DISCUSSION}

The purpose of our study was to retrospectively analyze the prevalence of LAA thrombus in patients continuously anticoagulated with apixaban for $\geq 4$ wk and evaluate for any cardiac risk factors or echocardiographic characteristics which may serve as predictors of thrombus formation.

\section{Prevalence of LAA thrombus detection}

To date, there remains limited data on the prevalence of LAA thrombus detection by TEE amongst patients with non-valvular AF on apixaban therapy. Multiple recent retrospective analyses have helped to elucidate the prevalence of LAA thrombus in 


\begin{tabular}{|c|c|c|c|c|c|c|}
\hline \multicolumn{7}{|l|}{ Apixaban } \\
\hline \multirow[t]{2}{*}{ Variable } & \multicolumn{3}{|c|}{ Unadjusted (univariate analysis) } & \multicolumn{3}{|c|}{ Adjusted (multivariate analysis) } \\
\hline & OR & $95 \% \mathrm{Cl}$ & $P$-value & OR & $95 \% \mathrm{Cl}$ & $P$-value \\
\hline $\mathrm{CHF}$ & 1.440 & $0.31-6.60$ & 0.6388 & & & \\
\hline Hypertension & 1.933 & $0.24-15.87$ & 0.5396 & & & \\
\hline Age $>65$ & 3.453 & $0.41-29.20$ & 0.2552 & & & \\
\hline Age $>75$ & 0.578 & $0.07-4.92$ & 0.6160 & & & \\
\hline Diabetes & 1.425 & $0.27-7.58$ & 0.6778 & & & \\
\hline Stroke & 2.177 & $0.25-18.85$ & 0.4800 & & & \\
\hline Vascular disease & 1.293 & $0.15-11.19$ & 0.8152 & & & \\
\hline $\mathrm{CHA}_{2} \mathrm{DS}_{2}$-VASc & 1.261 & $0.80-2.00$ & 0.3240 & & & \\
\hline Gender (female) & 0.631 & $0.12-3.32$ & 0.5866 & & & \\
\hline Persistent AF & 7.639 & $1.44-40.51$ & $0.0169^{1}$ & 7.427 & $1.02-53.92$ & 0.0474 \\
\hline LVEF $<30 \%$ & 4.725 & $1.01-22.17$ & $0.0489^{1}$ & 0.726 & $0.10-5.12$ & 0.7480 \\
\hline LVEF $<50 \%^{2}$ & 2.667 & $0.58-12.23$ & 0.2069 & & & \\
\hline Severe left atrial dilation ${ }^{1}$ & 8.877 & $1.27-61.85$ & $0.0275^{1}$ & 5.901 & $0.69-50.62$ & 0.1054 \\
\hline LAA velocity (decrease) $^{1}$ & 1.110 & $1.031-1.19$ & $0.0032^{1}$ & 1.086 & $1.010-1.187$ & 0.0489 \\
\hline LAA velocity $<40 \mathrm{~cm} / \mathrm{s}^{2}$ & 14.215 & $1.68-120.40$ & $0.0149^{2}$ & & & \\
\hline
\end{tabular}

${ }^{1}$ Significant factor in the univariate model which is used in the multivariate model;

${ }^{2}$ Significant factor in the univariate model but not considered in the multivariate model. AF: Atrial fibrillation; CHF: Congestive heart failure; CI: Confidence interval; LAA: Left atrial appendage; LVEF: Left ventricular ejection fraction; OR: Odds ratio.

patients treated with NOACs, in particular, patients undergoing catheter ablation $^{[18-20,22]}$. However, apixaban is often the least represented oral anticoagulant in these studies with a reported prevalence of $0 \%$ to $2.9 \%{ }^{[21]}$. In our study population, the prevalence of LAA thrombus was $3.1 \%$ despite $\geq 4 \mathrm{wk}$ of continuous anticoagulation which is consistent with previously published data from smaller cohorts when risk factors are considered. The cohort was at considerable risk given mean $\mathrm{CHA}_{2} \mathrm{DS}_{2}-$ VASc $2.83 \pm 1.62$ and $80.1 \%$ of patients with $\mathrm{CHA}_{2} \mathrm{DS}_{2}-\mathrm{VASc} \geq 2$.

\section{Predictors of LAA thrombus detection}

The presence of persistent AF, reduced LVEF, severe LA dilation, and reduced LAA velocity were identified as univariate predictors of LA thrombus detection in the apixaban cohort. Following evaluation with multivariate logistic regression, persistent AF and reduced LAA velocity were identified as independent predictors of LA thrombus detection. Commonly identified independent predictors of thrombus formation in recent studies include $\mathrm{CHF}$, persistent $\mathrm{AF}$, reduced $\mathrm{LVEF}$, and elevated $\mathrm{CHA}_{2} \mathrm{DS}_{2}-\mathrm{VASc}$ score ${ }^{[18-20]}$. Of note, apixaban was often the least represented NOAC in these studies and made minimal contribution to the population with thrombus. Finally, these analyses pooled vitamin K antagonist and NOAC data in order perform multivariate analysis with one exception, in which the authors describe only 1 independent predictor and report small sample size as a limitation ${ }^{[18-20]}$ CHA $_{2} \mathrm{DS}_{2}$ VASc score was not identified as a univariate predictor which is likely a result of the relatively small number of low-risk patients in our study population as only $19.9 \%$ of patients had $\mathrm{CHA}_{2} \mathrm{DS}_{2}-\mathrm{VASc}$ score $<2$. Of note, reduced LVEF $<30 \%$ was identified as a significant univariate predictor in both analyses, however was not determined to be a significant independent predictor. We believe that reduced LVEF is a significant predictor of thrombus formation as identified in similar studies with variable anticoagulation strategies and rates of compliance ${ }^{[0,13,19,20]}$. However, our result likely reflects a limitation of sample size as well as an inherent relationship between advanced cardiomyopathy and clinical/echocardiographic findings most prevalent in high-risk patients with AF.

\section{Rate of LAA thrombus resolution}

Data regarding thrombus resolution in patients prescribed apixaban has thus far been limited to case reports and small cohorts ${ }^{[19,20,26,27]}$. While data regarding thrombus resolution in patients prescribed warfarin is more prevalent, rates of resolution range 
Table 3 Clinical characteristics and thrombus resolution

\begin{tabular}{|c|c|c|c|c|c|c|c|c|c|c|c|}
\hline Study ID & $\begin{array}{l}\text { AC after } \\
\text { thrombus } \\
\text { identificat } \\
\text { ion }\end{array}$ & $\begin{array}{l}\text { Thrombus } \\
\text { resolution }\end{array}$ & $\begin{array}{l}\text { Duration } \\
\text { of } A C \text { (d) }\end{array}$ & $\begin{array}{l}\text { P2Y12 } \\
\text { inhibitor }\end{array}$ & Aspirin & LVEF (\%) & $\begin{array}{c}\text { LA } \\
\text { dilation }\end{array}$ & $\begin{array}{l}\text { Spontane } \\
\text { ous } \\
\text { contrast }\end{array}$ & $\begin{array}{c}\text { LAA } \\
\text { velocity } \\
(\mathrm{cm} / \mathrm{s})\end{array}$ & $\begin{array}{l}\text { Duration } \\
\text { of A-fib }\end{array}$ & $\begin{array}{l}\text { CHADS- } \\
\text { VASc } \\
\text { score }\end{array}$ \\
\hline \multicolumn{12}{|c|}{ Apixaban following index TEE $(n=6)$} \\
\hline LA-011 & Apixaban & Yes & 143 & No & No & 55 & Moderate & None & 30.4 & $\begin{array}{c}\text { Paroxysma } \\
1\end{array}$ & 3 \\
\hline LA-016 & Apixaban & Yes & 38 & Yes & Yes & 15 & Severe & Severe & 14.4 & $\begin{array}{c}\text { Paroxysma } \\
1\end{array}$ & 2 \\
\hline LA-017 & Apixaban & Yes & 175 & No & Yes & 15 & Severe & Mild & 34.0 & $\begin{array}{c}\text { Paroxysma } \\
1\end{array}$ & 4 \\
\hline LA-019 & Apixaban & Yes & 40 & No & No & 30 & Severe & None & 26.5 & $\begin{array}{c}\text { Paroxysma } \\
1\end{array}$ & 2 \\
\hline LA-020 & Apixaban & Yes & 56 & No & Yes & 25 & Severe & Moderate & 28.0 & Persistent & 3 \\
\hline \multirow[t]{3}{*}{ LA-005 } & Apixaban & No & 112 & No & No & 65 & Moderate & Moderate & 49.2 & Persistent & 4 \\
\hline & & $5 / 6$ & Mean 94.0 & & & & & & & & \\
\hline & & $(83.3 \%)$ & $\begin{array}{c}\text { Median } \\
84.0\end{array}$ & & & & & & & & \\
\hline
\end{tabular}

AC: Anticoagulation; A-fib: Atrial fibrillation; LA: Left atrium; LAA: Left atrial appendage; LVEF: Left ventricular ejection fraction; TEE: Transesophageal echocardiogram.

from $55 \%$ to $82 \%{ }^{[16,17,28]}$. In our limited cohort, we identified thrombus resolution in $83.3 \%$ of patients anticoagulated with apixaban $(n=6)$. Although all patients were confirmed to be compliant with continuous anticoagulation throughout the follow up period, there was significant heterogeneity in the duration of therapy prior to repeat cardiac imaging which limits our ability to draw conclusions regarding the optimal duration of anticoagulation. Regardless, apixaban appears to be a reasonable anticoagulation strategy in this population and warrants further investigation in prospective trial.

\section{Application of study findings}

A recent expert consensus statement recommends that current anticoagulation guidelines as they pertain to cardioversion of AF should be observed for patients presenting with AF prior to catheter ablation and that TEE is reasonable despite $\geq 3$ wk of continuous anticoagulation ${ }^{[1,2,7]}$. Two recent surveys, one including 16 Canadian centers and the other including 521 ablation centers in 24 countries, report that $>70 \%$ of ablation centers routinely utilized pre-procedure TEE in all patients ${ }^{[2,30]}$. One costeffectiveness analysis reports an incremental cost-effectiveness ratio of $\$ 226608$ per quality-adjusted life year for routine use of TEE in an unselected population prior to pulmonary vein isolation modeled with a $4 \%$ prevalence of thrombus. While the prevalence is likely overestimated, this analysis highlights the need to better identify patients with a high pretest probability of LAA thrombus despite continuous anticoagulation in order to improve the cost-benefit ratio of the procedure ${ }^{[31]}$. A trend toward more conservative use of pre-procedural TEE appears to be underway as one large ablation center reports a significant decline in the routine utilization of TEE from $86 \%$ to $42 \%$ over a 5 year period ${ }^{[22]}$. While another recent study completely eliminated pre-procedural TEE in favor of intracardiac echocardiography prior to AF ablation. Despite adequate imaging of the LAA in only $71 \%$ of patients, the authors report excellent outcomes ${ }^{[32]}$. This study is retrospective and meant to explore variables which could be predictors of thrombus formation in patients treated with apixaban. A prospective randomized trial would be needed to conclusively determine and validate a scoring system and/or various cutoffs. However, this may not be practical given the low event rate in this population. Nonetheless, we hope that our work can provide evidence to help guide the selection of patients for pre-procedural TEE.

\section{Study limitations}

Our study is limited by the retrospective nature of the data collected. In addition, we cannot objectively confirm $100 \%$ compliance with apixaban therapy as quantitative assays are not routinely used in clinical practice. Although we took great effort to exclude any patients with documented non-compliance, our ability to do so would be limited by the history provided and documentation of health care professionals.

In patients with non-valvular $\mathrm{AF}$ and a minimum of $4 \mathrm{wk}$ continuous oral 
anticoagulation with apixaban, the prevalence of LAA thrombus and LAA thrombus/dense SEC detected by TEE was $3.1 \%$ and $6.6 \%$, respectively. Both persistent AF and reduced LAA velocity were identified as independent predictors of LA thrombus detection in patients anticoagulated with apixaban. In addition, LVEF < $30 \%$ and severe LA dilation were identified as univariate predictors. We hope that the presence or absence of these clinical findings in addition to established risk factors can help guide the selection process for utilization of pre-procedural TEE in future patients with non-valvular AF anticoagulated with apixaban.

\section{ARTICLE HIGHLIGHTS}

\section{Research background}

The prevalence of left atrial appendage (LAA) thrombus detection by transesophageal echocardiogram (TEE) in patients anticoagulated for $\geq 4 \mathrm{wk}$ with apixaban is not well defined and predictors of LAA thrombus detection are not completely understood. Furthermore, the efficacy of apixaban to resolve pre-existing LAA thrombi is not well documented.

\section{Research motivation}

Prescriptions rates for non-vitamin $\mathrm{K}$ dependent oral anticoagulants are increasing on a yearly basis and further analysis of patients prescribed apixaban could have clinically meaningful implications. We aimed to identify significant predictors of LAA thrombus detection on TEE to aid in the selection process for screening in future patients undergoing direct current cardioversion or catheter ablation.

\section{Research objectives}

The purpose of our study was to retrospectively analyze the prevalence of LAA thrombus detection by TEE in patients continuously anticoagulated with apixaban for $\geq 4 \mathrm{wk}$ and evaluate for any cardiac risk factors or echocardiographic characteristics which may serve as predictors of thrombus formation.

\section{Research methods}

Clinical and echocardiographic data for 820 consecutive patients with atrial fibrillation (AF) undergoing TEE at Augusta University Medical Center over a four-year period were retrospectively analyzed. All patients (apixaban: 226) with non-valvular AF and documented compliance with apixaban for $\geq 4 \mathrm{wk}$ prior to index TEE were included.

\section{Research results}

Following $\geq 4$ wk of continuous anticoagulation with apixaban, the prevalence of LAA thrombus and LAA thrombus/dense spontaneous echocardiographic contrast was $3.1 \%$ and $6.6 \%$, respectively. Persistent AF, left ventricular ejection fraction $<30 \%$, severe LA dilation, and reduced LAA velocity were associated with thrombus formation. Following multivariate logistic regression, persistent $\mathrm{AF}$ (OR: 7.427; 95\%CI: 1.02 to 53.92; $P=0.0474)$, and reduced LAA velocity (OR: 1.086; $95 \% \mathrm{CI}: 1.010$ to $1.187 ; P=0.0489$ ) were identified as independent predictors of LAA thrombus. No Thrombi were detected in patients with a $\mathrm{CHA}_{2} \mathrm{DS}_{2}$-VASc score $\leq 1$.

\section{Research conclusions}

Among patients with non-valvular $\mathrm{AF}$ and $\geq 4 \mathrm{wk}$ of anticoagulation with apixaban, the prevalence of LAA thrombus detected by TEE was $3.1 \%$. This suggests that continuous therapy with apixaban does not completely eliminate the risk of LAA thrombus and that TEE prior to cardioversion or catheter ablation may be of benefit in patients with multiple risk factors.

\section{Research perspectives}

Compliance with non-vitamin $\mathrm{K}$ oral anticoagulants reduces but does not eliminate the prevalence of thrombus detection by TEE. However, available cost-effectiveness analysis reports that pre-procedural TEE is unlikely to be cost-effective in an unselected population. Therefore, there is a need to better identify patients with increased pretest probability of LAA thrombus in order to improve the cost-benefit ratio of the procedure. It is our hope that identification of additional clinical and echocardiographic characteristics; in addition to established risk factors, can help guide the selection process for utilization of pre-procedural TEE

\section{REFERENCES}

1 January CT, Wann LS, Alpert JS, Calkins H, Cigarroa JE, Cleveland JC, Conti JB, Ellinor PT, Ezekowitz MD, Field ME, Murray KT, Sacco RL, Stevenson WG, Tchou PJ, Tracy CM, Yancy CW; ACC/AHA Task Force Members. 2014 AHA/ACC/HRS guideline for the management of patients with atrial fibrillation: a report of the American College of Cardiology/American Heart Association Task Force on practice guidelines and the Heart Rhythm Society. Circulation 2014; 130: e199-e267 [PMID: 24682347 DOI: 10.1161/CIR.0000000000000041]

2 Kirchhof P, Benussi S, Kotecha D, Ahlsson A, Atar D, Casadei B, Castella M, Diener HC, Heidbuchel H, Hendriks J, Hindricks G, Manolis AS, Oldgren J, Popescu BA, Schotten U, Van Putte B, Vardas P; ESC Scientific Document Group. 2016 ESC Guidelines for the management of atrial fibrillation developed in 
collaboration with EACTS. Eur Heart J 2016; 37: 2893-2962 [PMID: 27567408 DOI: 10.1093/eurheartj/ehw210]

3 Al-Saady NM, Obel OA, Camm AJ. Left atrial appendage: structure, function, and role in thromboembolism. Heart 1999; 82: 547-554 [PMID: 10525506 DOI: 10.1136/hrt.82.5.547]

4 Manning WJ, Weintraub RM, Waksmonski CA, Haering JM, Rooney PS, Maslow AD, Johnson RG, Douglas PS. Accuracy of transesophageal echocardiography for identifying left atrial thrombi. A prospective, intraoperative study. Ann Intern Med 1995; 123: 817-822 [PMID: 7486462 DOI: 10.7326/0003-4819-123-11-199512010-00001]

5 Manning WJ, Silverman DI, Gordon SP, Krumholz HM, Douglas PS. Cardioversion from atrial fibrillation without prolonged anticoagulation with use of transesophageal echocardiography to exclude the presence of atrial thrombi. $N$ Engl J Med 1993; 328: 750-755 [PMID: 8437595 DOI: 10.1056/NEJM199303183281102]

6 Klein AL, Grimm RA, Murray RD, Apperson-Hansen C, Asinger RW, Black IW, Davidoff R, Erbel R, Halperin JL, Orsinelli DA, Porter TR, Stoddard MF; Assessment of Cardioversion Using Transesophageal Echocardiography Investigators. Use of transesophageal echocardiography to guide cardioversion in patients with atrial fibrillation. $N$ Engl J Med 2001; 344: 1411-1420 [PMID: 11346805 DOI: 10.1056/NEJM200105103441901]

7 Calkins H, Hindricks G, Cappato R, Kim YH, Saad EB, Aguinaga L, Akar JG, Badhwar V, Brugada J, Camm J, Chen PS, Chen SA, Chung MK, Nielsen JC, Curtis AB, Davies DW, Day JD, d'Avila A, de Groot NMSN, Di Biase L, Duytschaever M, Edgerton JR, Ellenbogen KA, Ellinor PT, Ernst S, Fenelon G, Gerstenfeld EP, Haines DE, Haissaguerre M, Helm RH, Hylek E, Jackman WM, Jalife J, Kalman JM, Kautzner J, Kottkamp H, Kuck KH, Kumagai K, Lee R, Lewalter T, Lindsay BD, Macle L, Mansour M, Marchlinski FE, Michaud GF, Nakagawa H, Natale A, Nattel S, Okumura K, Packer D, Pokushalov E, Reynolds MR, Sanders P, Scanavacca M, Schilling R, Tondo C, Tsao HM, Verma A, Wilber DJ, Yamane T. 2017 HRS/EHRA/ECAS/APHRS/SOLAECE expert consensus statement on catheter and surgical ablation of atrial fibrillation. Heart Rhythm 2017; 14: e275-e444 [PMID: 28506916 DOI: 10.1016/j.hrthm.2017.05.012]

8 Wallace TW, Atwater BD, Daubert JP, Voora D, Crowley AL, Bahnson TD, Hranitzky PM. Prevalence and clinical characteristics associated with left atrial appendage thrombus in fully anticoagulated patients undergoing catheter-directed atrial fibrillation ablation. J Cardiovasc Electrophysiol 2010; 21: 849-852 [PMID: 20158561 DOI: 10.1111/j.1540-8167.2010.01729.x]

9 Puwanant S, Varr BC, Shrestha K, Hussain SK, Tang WH, Gabriel RS, Wazni OM, Bhargava M, Saliba WI, Thomas JD, Lindsay BD, Klein AL. Role of the CHADS2 score in the evaluation of thromboembolic risk in patients with atrial fibrillation undergoing transesophageal echocardiography before pulmonary vein isolation. J Am Coll Cardiol 2009; 54: 2032-2039 [PMID: 19926009 DOI: 10.1016/j.jacc.2009.07.037]

10 Yamamoto M, Seo Y, Kawamatsu N, Sato K, Sugano A, Machino-Ohtsuka T, Kawamura R, Nakajima H, Igarashi M, Sekiguchi Y, Ishizu T, Aonuma K. Complex left atrial appendage morphology and left atrial appendage thrombus formation in patients with atrial fibrillation. Circ Cardiovasc Imaging 2014; 7: 337 343 [PMID: 24523417 DOI: 10.1161/CIRCIMAGING.113.001317]

11 Calvo N, Mont L, Vidal B, Nadal M, Montserrat S, Andreu D, Tamborero D, Pare C, Azqueta M, Berruezo A, Brugada J, Sitges M. Usefulness of transoesophageal echocardiography before circumferential pulmonary vein ablation in patients with atrial fibrillation: is it really mandatory? Europace 2011; 13: 486491 [PMID: 21186230 DOI: 10.1093/europace/euq456]

12 Scherr D, Dalal D, Chilukuri K, Dong J, Spragg D, Henrikson CA, Nazarian S, Cheng A, Berger RD, Abraham TP, Calkins H, Marine JE. Incidence and predictors of left atrial thrombus prior to catheter ablation of atrial fibrillation. J Cardiovasc Electrophysiol 2009; 20: 379-384 [PMID: 19017348 DOI: 10.1111/j.1540-8167.2008.01336.x]

13 McCready JW, Nunn L, Lambiase PD, Ahsan SY, Segal OR, Rowland E, Lowe MD, Chow AW. Incidence of left atrial thrombus prior to atrial fibrillation ablation: is pre-procedural transoesophageal echocardiography mandatory? Europace 2010; 12: 927-932 [PMID: 20304842 DOI: 10.1093/europace/euq074]

14 Savarese G, Giugliano RP, Rosano GM, McMurray J, Magnani G, Filippatos G, Dellegrottaglie S, Lund LH, Trimarco B, Perrone-Filardi P. Efficacy and Safety of Novel Oral Anticoagulants in Patients With Atrial Fibrillation and Heart Failure: A Meta-Analysis. JACC Heart Fail 2016; 4: 870-880 [PMID: 27614940 DOI: 10.1016/j.jchf.2016.07.012]

15 Ruff CT, Giugliano RP, Braunwald E, Hoffman EB, Deenadayalu N, Ezekowitz MD, Camm AJ, Weitz JI, Lewis BS, Parkhomenko A, Yamashita T, Antman EM. Comparison of the efficacy and safety of new oral anticoagulants with warfarin in patients with atrial fibrillation: a meta-analysis of randomised trials. Lancet 2014; 383: 955-962 [PMID: 24315724 DOI: 10.1016/S0140-6736(13)62343-0]

16 Jaber WA, Prior DL, Thamilarasan M, Grimm RA, Thomas JD, Klein AL, Asher CR. Efficacy of anticoagulation in resolving left atrial and left atrial appendage thrombi: A transesophageal echocardiographic study. Am Heart J 2000; 140: 150-156 [PMID: 10874278 DOI: 10.1067/mhj.2000.106648]

17 Seidl K, Rameken M, Drögemüller A, Vater M, Brandt A, Schwacke H, Bergmeier C, Zahn R, Senges J. Embolic events in patients with atrial fibrillation and effective anticoagulation: value of transesophageal echocardiography to guide direct-current cardioversion. Final results of the Ludwigshafen Observational Cardioversion Study. J Am Coll Cardiol 2002; 39: 1436-1442 [PMID: 11985904 DOI: 10.1016/S0735-1097(02)01785-0]

18 Wyrembak J, Campbell KB, Steinberg BA, Bahnson TD, Daubert JP, Velazquez EJ, Samad Z, Atwater BD. Incidence and Predictors of Left Atrial Appendage Thrombus in Patients Treated With Nonvitamin K Oral Anticoagulants Versus Warfarin Before Catheter Ablation for Atrial Fibrillation. Am J Cardiol 2017; 119: 1017-1022 [PMID: 28153350 DOI: 10.1016/j.amjcard.2016.12.008]

19 Frenkel D, D'Amato SA, Al-Kazaz M, Markowitz SM, Liu CF, Thomas G, Ip JE, Sharma SK, Yang H, Singh P, Lerman BB, Cheung JW. Prevalence of Left Atrial Thrombus Detection by Transesophageal Echocardiography: A Comparison of Continuous Non-Vitamin K Antagonist Oral Anticoagulant Versus Warfarin Therapy in Patients Undergoing Catheter Ablation for Atrial Fibrillation. JACC Clin Electrophysiol 2016; 2: 295-303 [PMID: 29766887 DOI: 10.1016/j.jacep.2016.01.004]

20 Da Costa A, Delolme C, Guichard JB, Gerbay A, Pierrard R, Romeyer-Bouchard C, Isaaz K. Comparison of prevalence and management of left atrial appendage thrombi under old and new anticoagulants prior to left atrial catheter ablation. Am Heart J 2017; 193: 8-15 [PMID: 29129259 DOI: 10.1016/j.ahj.2017.07.016] 
21 Flaker G, Lopes RD, Al-Khatib SM, Hermosillo AG, Hohnloser SH, Tinga B, Zhu J, Mohan P, Garcia D, Bartunek J, Vinereanu D, Husted S, Harjola VP, Rosenqvist M, Alexander JH, Granger CB; ARISTOTLE Committees and Investigators. Efficacy and safety of apixaban in patients after cardioversion for atrial fibrillation: insights from the ARISTOTLE Trial (Apixaban for Reduction in Stroke and Other

Thromboembolic Events in Atrial Fibrillation). J Am Coll Cardiol 2014; 63: 1082-1087 [PMID: 24211508 DOI: 10.1016/j.jacc.2013.09.062]

22 Balouch M, Gucuk Ipek E, Chrispin J, Bajwa RJ, Zghaib T, Berger RD, Ashikaga H, Calkins H, Nazarian $\mathrm{S}$, Marine JE, Spragg DD. Trends in Transesophageal Echocardiography Use, Findings, and Clinical Outcomes in the Era of Minimally Interrupted Anticoagulation for Atrial Fibrillation Ablation. JACC Clin Electrophysiol 2017; 3: 329-336 [PMID: 29759444 DOI: 10.1016/j.jacep.2016.09.011]

23 Marzec LN, Wang J, Shah ND, Chan PS, Ting HH, Gosch KL, Hsu JC, Maddox TM. Influence of Direct Oral Anticoagulants on Rates of Oral Anticoagulation for Atrial Fibrillation. J Am Coll Cardiol 2017; 69: 2475-2484 [PMID: 28521884 DOI: 10.1016/j.jacc.2017.03.540]

24 Lip GY, Nieuwlaat R, Pisters R, Lane DA, Crijns HJ. Refining clinical risk stratification for predicting stroke and thromboembolism in atrial fibrillation using a novel risk factor-based approach: the euro heart survey on atrial fibrillation. Chest 2010; 137: 263-272 [PMID: 19762550 DOI: 10.1378/chest.09-1584] Fatkin D, Kelly RP, Feneley MP. Relations between left atrial appendage blood flow velocity, spontaneous echocardiographic contrast and thromboembolic risk in vivo. J Am Coll Cardiol 1994; 23: 961-969 [PMID: 8106703 DOI: 10.1016/0735-1097(94)90644-0]

26 Dobashi S, Fujino T, Ikeda T. Use of apixaban for an elderly patient with left atrial thrombus. BMJ Case Rep 2014; 2014: pii: bcr2014203870 [PMID: 24962484 DOI: 10.1136/bcr-2014-203870]

27 Miwa Y, Minamishima T, Sato T, Sakata K, Yoshino H, Soejima K. Resolution of a warfarin and dabigatran-resistant left atrial appendage thrombus with apixaban. $J$ Arrhythm 2016; 32: 233-235 [PMID: 27354873 DOI: 10.1016/j.joa.2016.01.009]

28 Corrado G, Tadeo G, Beretta S, Tagliagambe LM, Manzillo GF, Spata M, Santarone M. Atrial thrombi resolution after prolonged anticoagulation in patients with atrial fibrillation. Chest 1999; 115: 140-143 [PMID: 9925075 DOI: 10.1378/chest.115.1.140]

29 Cappato R, Calkins H, Chen SA, Davies W, Iesaka Y, Kalman J, Kim YH, Klein G, Natale A, Packer D, Skanes A, Ambrogi F, Biganzoli E. Updated worldwide survey on the methods, efficacy, and safety of catheter ablation for human atrial fibrillation. Circ Arrhythm Electrophysiol 2010; 3: 32-38 [PMID: 19995881 DOI: 10.1161/CIRCEP.109.859116]

30 Awad S, Mohajer K, Baranchuk A, Pal RS. Current clinical practice of transesophageal echocardiography and cardiac computed tomography prior to atrial fibrillation ablation in Canada. Int J Cardiol 2015; 189: 300-301 [PMID: 25967570 DOI: 10.1016/j.ijcard.2015.03.318]

31 Gula LJ, Massel D, Redfearn DP, Krahn AD, Yee R, Klein GJ, Skanes AC. Impact of routine transoesophageal echocardiography on safety, outcomes, and cost of pulmonary vein ablation: inferences drawn from a decision analysis model. Europace 2010; 12: 1550-1557 [PMID: 20716548 DOI: 10.1093/europace/euq306]

32 Di Biase L, Briceno DF, Trivedi C, Mohanty S, Gianni C, Burkhardt JD, Mohanty P, Bai R, Gunda S, Horton R, Bailey S, Sanchez JE, Al-Ahmad A, Hranitzky P, Gallinghouse GJ, Reddy YM, Zagrodzky J, Hongo R, Beheiry S, Lakkireddy D, Natale A. Is transesophageal echocardiogram mandatory in patients undergoing ablation of atrial fibrillation with uninterrupted novel oral anticoagulants? Results from a prospective multicenter registry. Heart Rhythm 2016; 13: 1197-1202 [PMID: 26994940 DOI: 10.1016/j.hrthm.2016.03.024]

P- Reviewer: Hochholzer W, Kharlamov AN S- Editor: Ji FF L- Editor: A E- Editor: Wu YXJ 


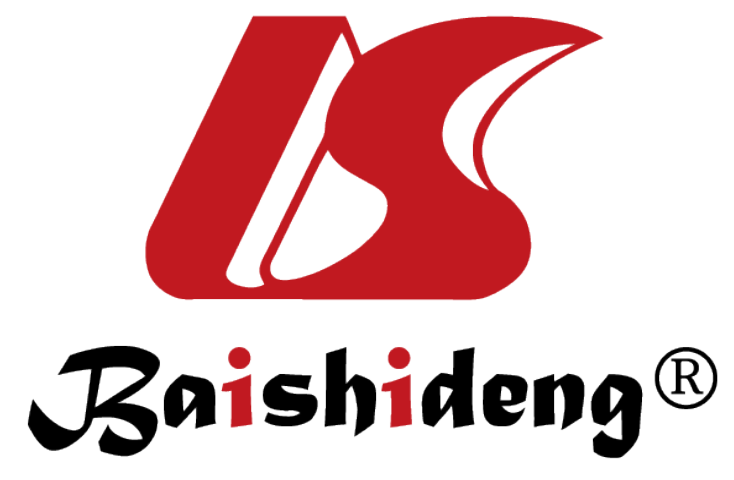

Published By Baishideng Publishing Group Inc 7901 Stoneridge Drive, Suite 501, Pleasanton, CA 94588, USA Telephone: +1-925-2238242

Fax: +1-925-2238243

E-mail: bpgoffice@wjgnet.com

Help Desk: https://www.f6publishing.com/helpdesk

https://www.wjgnet.com

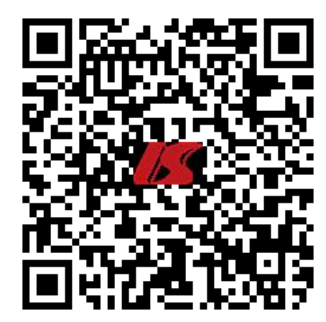

